Mirai. Estudios Japoneses

ISSN-e: 1988-2378

http://dx.doi.org/10.5209/MIRA.57110

\title{
Huellas de Japón en las crónicas misioneras del siglo XVII: la historia de Marcelo de Ribadeneira ${ }^{1}$
}

Dra. Anna Busquets Alemany ${ }^{2}$

Resumen: El objetivo de esta investigación es contextualizar la llegada de Marcelo de Ribadeneria a Japón y presentar la imagen que ofrece de este país en su voluminosa obra Historia de las Islas del archipiélago filipino y reinos de la gran China, Tartaria, Cochinchina, Malaca, Siam, Cambodge y Japón, que se publicó en Barcelona en 1601.

Palabras clave: Ribadeneria; Franciscanos; Japón; islas Filipinas

[en] Vestiges of Japan in missionary chronicles of the $17^{\text {th }}$ century: the history of Marcelo de Ribadeneira

Abstract: The purpose of this chapter is to contextualize the arrival of Marcelo de Ribadeneira in Japan and to analyse the image he offers of this country in his voluminous work Historia de las Islas del archipiélago Filipino y reinos de la gran China, Tartaria, Cochinchina, Malaca, Siam, Camnvlmlogmbodge y Japón, which was published in Barcelona in 1601.

Keywords: Ribadeneira; Franciscans; Japan; Philippine islands.

Sumario. 1. Ribadeneira y su Historia. 2. Japón en la Historia de Ribadeneira. 3. Consideraciones finales.

Cómo citar: Busquets Alemany, A. (2017). Huellas de Japón en las crónicas misioneras del siglo XVII: la historia de Marcelo de Ribadeneira (2017), en Mirai. Estudios Japoneses 1, 2017, 169-180.

El 27 de agosto de 1594, el franciscano Marcelo de Ribadeneira ${ }^{3}$ desembarcó en el puerto de Hirado, en la costa sur de Japón, y permaneció en este país hasta 1597, momento en el que debido a la persecución que se desató contra el cristianismo — cuyo punto álgido llegó en febrero de ese año con los martirios de Nagasaki ${ }^{4}$ -

Esta investigación forma parte del Proyecto HAR2015-64014-C3-1-R.

2 Universitat Oberta de Catalunya (UOC).

abusquetsa@uoc.edu

3 Algunos datos de la biografía de este religioso, tales como el lugar de nacimiento, la fecha de su muerte o cuándo y cómo ingresó en la orden de los franciscanos, están todavía sin esclarecer. Para seguir los principales episodios de su vida véase CAStro, Manuel de (1979): "Fr. Marcelo de Ribadeneira, OFM, vida y escritos". En: SÁnchez, Víctor / Fuertes, Cayetano S. (dirs.): España en Extremo Oriente. Filipinas, China, Japón. Presencia franciscana 15781978. Madrid: Editorial Cisneros, pp. 181-246. También RibadENEIRA, Marcelo de, OFM (1601): Historia de las islas del archipiélago filipino y reinos de la gran China, Tartaria, Cochinchina, Malaca, Siam, Cambodge y Japón, Juan R. Legísima (edición, prólogo y notas). Madrid: Católica, 1947; Álvarez-Taladriz, José Luis (1973): Documentos franciscanos de la cristiandad de Japón (1593-1597): relaciones e informaciones. Japón: Eikodo.

4 Con esta denominación se hace referencia al episodio acontecido en la ciudad japonesa de Nagasaki el 5 de febrero de 1597, en el que fueron ejecutados los primeros mártires japoneses debido a que hubo contra el cristianismo durante el gobierno de Toyotomi Hideyoshi. De acuerdo con Castro, los 26 mártires cristianos eran: 
se vio obligado a esconderse en Macao y luego a escapar de allí. Consiguió llegar a Manila a principios del año siguiente, en 1598, y mientras estaba en las Filipinas sus superiores le encargaron preparar un relato sobre la situación del cristianismo en Japón. Por ello, aprovechó su estancia en las islas para documentarse y recabar toda la información que le fue posible, mostrando especial interés por las persecuciones que habían vivido sus compañeros en Japón y de las que él pudo salvarse. Al poco tiempo se embarcó rumbo a España, vía México. Se sabe que llegó a Sevilla en 1599, que de allí se dirigió a Madrid y luego a Roma para, como él mismo señala, "dar cuenta a su Santidad y a la majestad católica del rey nuestro señor de cosas muy graves de que era necesario darse verdadera información"5. En este mismo período fue nombrado Procurador de la causa de la beatificación de los mártires de Japón ${ }^{6}$. En 1601 volvía a estar en España y, de acuerdo con sus biógrafos, presentó a Felipe III su obra Historia eclesiástica de las islas Filipinas y reinos de Japón, de la que no se conserva ningún ejemplar ${ }^{7}$. Ese mismo año viajó a Barcelona donde imprimió su voluminosa obra Historia de las islas del Archipiélago filipino y reinos de la gran China, Tartaria, Cochinchina, Malaca, Siam, Cambodge y Japón (en adelante, Historia), tras haber obtenido las licencias necesarias. A partir de este momento, tuvo que regresar a Roma para hacer frente a las diferentes acusaciones que los jesuitas presentaron a la Inquisición contra su obra. Se han conservado algunos de estos escritos acusatorios contra Ribadeneira — como por ejemplo las Obiectiones — así como también varios textos que Ribadeneira elaboró para defenderse y argumentar el valor de sus escritos - entre ellos, las Responsiones ${ }^{8}$. En este artículo dejaremos de lado las acusaciones, réplicas y contrarréplicas a raíz de los diversos escritos de Ribadeneira y nos centraremos en su Historia y, en concreto, en la imagen que en ella se proyecta de Japón.

\section{Ribadeneira y su Historia}

Ribadeneira estuvo en Japón durante casi tres años y, como se ha mencionado anteriormente, a su regreso a las Filipinas inició el trabajo de escribir una obra que presentara el estado de las misiones en Asia. Para ello, el franciscano ideó una voluminosa obra que presentara el estado de las misiones franciscanas en los diferentes países en los que ya se habían establecido. Para ello, y para mayor claridad para el lector, dispuso su Historia en seis libros, organizados internamente a partir de capítulos que recogen los principales

\footnotetext{
6 franciscanos, 17 terciarios franciscanos japoneses y 3 hermanos japoneses de la Compañía de Jesús. Véase CAstro, Manuel de (1979): "Fr. Marcelo de Ribadeneira”, op. cit., p. 205. La bibliografía sobre este asunto es muy extensa. Se citan a continuación algunos trabajos que ofrecen una buena síntesis de lo acontecido. LANZAco Salafranca, Federico (2011): "Un siglo de comercio y evangelización por España-Portugal en el Extremo Oriente, a través de las dos rutas marítimas del Patronato Español (Sevilla, Acapulco, Manila, Japón) y del Padroado Portugués (Lisboa, Cabo Buena Esperanza, Goa, Macao, Nagasaki). En La recepción del imaginario japonés en la literatura inglesa del siglo XIX. Universidad de Valladolid. http://www.uatatumi.org/lanzaco. pdf [Consulta: 01-09-2016]; TAKIZAWA, Osami: "El testimonio de los mártires en Japón”. En: BarLÉs, Elena y AlmazÁn, David (coords.): Japón y el mundo actual. Zaragoza: Prensas Universitarias de Zaragoza, 2011, pp. 59-80; CABeZAs, Antonio: El siglo ibérico de Japón. La presencia Hispano-Portuguesa en Japón (1543-1643). Valladolid: Universidad de Valladolid, 2012, pp. 249-257.

5 Ribadeneira, Marcelo de (1601): Historia de las islas ..., op. cit., p. 7. Las citas que se incluyen en este artículo proceden todas de la edición publicada en Madrid en 1947 y referenciada en la nota 2 de este trabajo.

6 Castro, Manuel de (1979): “Fr. Marcelo de Ribadeneira”, op. cit., p. 210.

Ibid., p. 212.

Ibid., p. 214.
} 
logros. El primer libro está dedicado a las islas Filipinas y a la entrada de los franciscanos allí. El segundo, está centrado en el reino de China y de qué manera los franciscanos lograron introducirse en aquel país. En este mismo libro, además, añade algunas notas relativas a la evangelización en Siam [Tailandia], Cochinchina [Vietnam], Malaca y Camboya. En el tercer libro, Ribadeneira presenta la biografía de más de una treintena de religiosos cuyas vidas estuvieron vinculadas a la evangelización en las diferentes misiones que los franciscanos tenían en Asia. Los capítulos cuarto, quinto y sexto están centrados en el reino de Japón y la labor que los franciscanos hicieron allí. El grueso de las noticias descriptivas de Japón se concentra fundamentalmente en el libro cuarto. Ahora bien, debido a la abundancia de detalles que ofrece el relato de Ribadeneira, también en los libros quinto y sexto es posible observar interesantes detalles sobre el país nipón que aparecen entremezclados en los relatos de las vidas de los franciscanos que estuvieron en este país y los episodios en los que se vieron envueltos. Ribadeneria ofrece una pormenorizada explicación sobre la entrada de los franciscanos en Japón, de qué manera se relacionaron y negociaron con las autoridades locales y cómo, tras conseguir los permisos necesarios, pudieron edificar casas, crear conventos y también hospitales. Como señala Barlés, cuando Ribadeneira explica estos temas "ensalza especialmente las labores sociales y evangélicas efectuadas por los religiosos, subrayando su dedicación a los más pobres y enfermos" ${ }^{\text {"9 }}$. Los años que Ribadeneira estuvo en Japón, así como la extensa información que recabó sobre este país, provocaron que sus compañeros de orden consideraran que todos los "negocios que tocaban al Japón se dejaban exclusivamente a cargo del padre Marcelo de Ribadeneria" .

Para la elaboración de su voluminosa Historia, las fuentes que Ribadeneria utilizó pueden agruparse en tres grandes bloques. En primer lugar, el franciscano incorpora una parte importante de la información procedente de su propia experiencia, que es especialmente relevante en todas las cuestiones de Japón. A lo largo de los capítulos en los que trata aspectos relacionados con el país nipón, recuerda de manera reiterada al lector que toda la información que allí incorpora procede de lo que él vio durante su estancia en aquel país. Por ello, expresiones del tipo "me pareció que sería bien poner una breve suma de lo que vi y supe en Japón" 11 son frecuentes a lo largo del relato. Además, tal como señala Álvarez-Taladriz, en el título de la edición original de la Historia se expresa que el autor fue "testigo de vista del admirable martirio" y, para que el lector no tenga ninguna duda, Ribadeneira asegura en el texto que encabeza el primer libro haber estado "viendo por mis propios ojos desde el navío donde estaba con otros tres hermanos míos presos, a mis santos compañeros y a los demás mártires crucificar"12. En segundo lugar, Ribadeneria incorpora testimonios de primera mano a los que tuvo acceso, especialmente informaciones que otros misioneros compartieron con él y con los que pudo charlar tanto durante su estancia en Japón como en Manila. Y finalmente, también usa las informaciones procedentes de los textos de otros misioneros para referir los progresos y el estado de la cristiandad en los diferentes países que incluye en su obra. Ribadeneria otorga

9 Barlés, Elena (2013): “Testimonios de las huellas de Japón en España”. En: KawAmura, Yayoi (ed.): Lacas Namban. Huellas de Japón en España. IV Centenario del viaje de Hasekura. Madrid: Ministerio de Cultura, Museo de Artes Decorativas, Fundación Japón, pp. 163-202. Sobre las obras de caridad véase por ejemplo RIBADENEIRA, Marcelo de (1601): Historia ..., op. cit., pp. 377-383.

$10 \quad$ Ibid., p. xiii.

11 Ibid., p. 321.

12 Álvarez-Taladriz, José Luis (ed.) (1973): Documentos franciscanos ... op. cit., pp.151-152. 
total credibilidad tanto a las informaciones procedentes de otros religiosos como a la procedente de la documentación que afirma haber consultado ${ }^{13}$.

A pesar de todos los países incluidos en el título de la obra, dos son los focos que concentran la atención del franciscano, China y Japón, siendo éste último el más importante sin duda alguna. Cuando trata el caso de China, seguramente por las noticias que sobre este país ya circulaban en Europa —en especial en la obra del agustino González de Mendoza, aludida por Ribadeneira en su Historia - , señala que su intención no es "historiar las costumbres de aquel gran reino, por estar ya largamente referidas en la sobredicha historia" 14 . Sin embargo, a pesar de lo manifestado, acaba incluyendo algunos datos generales relativos a China, sus costumbres, organización política o los principales elementos de su religiosidad, en los que sigue lo ya apuntado por González de Mendoza en su Historia de las cosas más notables, ritos y costumbres del gran reino de la China, que había sido publicada en $1585^{15}$.

En lo relativo a Japón, ocurre algo similar. El objetivo inicial de Ribadeneira es centrarse en la situación de la misión franciscana en este país y por ello escribe: "pretendiendo solamente escribir de propósito las cosas tocantes a mi Religión y provincia de San Gregorio, de lo que en casi tres años que estuve en Japón vi y supe"16. Sin embargo, dado que considera necesario esclarecer algunos aspectos de los que afirma existen informaciones que no le merecen credibilidad - especialmente en lo concerniente a los ritos y ceremonias religiosas en Japón — Ribadeneira acaba incorporando, como en el caso de China, algunas noticias descriptivas del mundo japonés, tales como la situación del reino, los principales productos, la organización interna, las principales ceremonias, las sectas, así como algunos aspectos relacionados con sus costumbres, su lengua y su escritura. En el prólogo de su obra, escribe lo siguiente:

De las cosas de Japón tampoco hay razón de dudar, pues de muchas costumbres, ritos y ceremonias de aquel reino, no por cartas que de allá han venido se tiene ya mucha noticia, y de las que han sucedido, de nuevo han sido tantos los historiadores, y en sus relaciones tan varios, que me pareció tenía obligación de dar noticia de lo verdadero, para que ni la pasión hable, ni la sinrazón reine, ni el poder y diligencia humana encubra verdades, sino que la verdad salga a luz de victorias enriquecida. Y aunque la historia de los mártires confío en el Señor será de edificación y gusto por corresponder a la variedad de los gustos, me pareció entretejer algo de las sectas de Japón, porque servirán, viendo la ceguedad de aquellos idólatras, para que conozcamos los bienes que de la fe nos nacen ${ }^{17}$.

Para comprender el relato que Ribadeneira hace de los asuntos relativos a Japón es necesario, como mínimo, tener en cuenta dos aspectos. Por un lado, el contexto de los contactos que desde hacía unos años se habían establecido entre Japón y las

\footnotetext{
Ribadeneira, Marcelo de (1601): Historia ..., op. cit., pp. 7-9.

Ibid., p. 115.

"Bien sé que no faltará quien diga que de las grandezas de la gran China está hecha una larga historia que escribió el padre Mendoza". Ibidem, p. 8; "Aunque el Padre Mendoza, en la historia que hizo del gran Reino de la China, aprovechándose (como queda dicho en el prólogo) de las relaciones que los religiosos que estuvieron allá le dieron". Ibid., p. 115.

16 Ibid., p. 9.

17 Ibid., p. 8.
} 
Filipinas; por el otro, el contexto de rivalidad que existía entre Portugal y Castilla en Asia y también entre las órdenes mendicantes y los jesuitas.

En relación con el primer aspecto, la llegada de Ribadeneira a Japón debe enmarcarse en el contexto de las comunicaciones que desde hacía un tiempo se habían establecido entre Japón y Manila mediante la fórmula de embajadas o intercambios comerciales $^{18}$. En concreto, Ribadeneria llegó a Japón en la embajada que el gobernador de Manila, Luis Pérez Dasmariñas, envió a Toyotomi Hideyoshi a mediados del año $1594^{19}$. En la delegación que salió de Filipinas viajaban cuatro franciscanos, dirigidos por fray Jerónimo de Jesús, aunque uno de ellos pereció durante el camino. Escribe el propio Ribadeneira en su Historia:

Fuimos enviados cuatro religiosos, fray Agustín Rodríguez, fray Andrés de San Antonio, fray Jerónimo de Jesús y yo a Japón, para ayudar a los cuatro religiosos que allí estaban. Y aunque por la mar tuvimos los acostumbrados trabajos de hambre y tormentas, lo que más pena nos dió fué la muerte del hermano fray Andrés de San Antonio, religioso de mucha santidad ${ }^{20}$.

Como integrante de la embajada, el principal motivo del viaje de Ribadeneria a Japón era entregar a Toyotomi Hideyoshi "presente y embajada de parte del gobernador, don Luis de las Mariñas [...] para confirmar las amistades que el año antes había hecho el santo mártir fray Pedro Bautista"21. A lo largo de la Historia, Ribadeneira ofrece abundantes detalles acerca de su viaje desde Manila y del trato que recibieron por parte de las autoridades locales cuando llegaron a Japón. El franciscano destaca, por ejemplo, el carácter hospitalario de los japoneses y señala que era tal que incluso fueron "aposentados en casa del gobernador de Miaco"22. Sin embargo, como religioso y misionero existía otro motivo mucho más importante para él, ayudar a la incipiente comunidad de franciscanos que ya estaba instalada en Japón y comenzar a trabajar en la evangelización de aquella tierra. Por este motivo, Ribadeneira señala que "sólo vivía en nosotros el deseo de vernos en Miaco con nuestros hermanos, los cuales según los japoneses nos decían, eran muy favorecidos del rey"23.

En cuanto al segundo aspecto, es importante señalar que desde 1493 con la bula Inter Caetera del Papa Alejandro VI —que intentaba establecer una repartición entre

18 El año anterior, el gobernador Gómez Pérez Dasmariñas había enviado una embajada a Hideyoshi encabezada por el franciscano San Pedro Bautista. Ribadeneira incorpora en su Historia la carta de la primera embajada que hubo, la que Hideyoshi envió al gobernador Gómez Pérez Dasmariñas, en la que exigía una respuesta inmediata como señal de amistad a fin de evitar una posible invasión. También incorpora la carta de respuesta que el gobernador envió mediante la embajada protagonizada por el dominico Juan Cobo. En concreto véase: Ibid., pp. 328-331. Para un estudio detallado de las distintas embajadas entre Japón y Manila véase Borao, José Eugenio (2005): "La colonia de japoneses en Manila en el marco de las relaciones de Filipinas y Japón en los siglos XVI y XVII". En: Cuadernos Canela, nº17, pp. 25-53; Sola, Emilio (2012): Historia de un desencuentro. España y Japón, 1580-1614. Archivo de la Frontera. http://www.archivodelafrontera.com/wp-content/uploads/2012/05/ Espana-y-Japon-XVI-XVII-Desencuentro.pdf [Consulta: 14/06/2017]

19 En la Historia de Ribadeneira aparece referido como Taicosama. Toyotomi Hideyoshi (1536-1598), daimio que ostentó el suficiente poder para implementar sus reformas que asentaron las bases del shogunato Tokugawa (1600-1868).

20 Ribadeneira, Marcelo de (1601): Historia ..., op. cit., pp. 343-344.

21 Ibid., p. 344.

22 Antigua denominación de Kioto.

23 Ribadeneira, Marcelo de (1601): Historia..., op. cit., p. 344. 
Castilla y Portugal de las tierras descubiertas y por descubrir-, Castilla y Portugal habían estado en pugna y ninguno de los documentos que intentaron resolver esta rivalidad puso fin al conflicto. Es más, tal como señala Molinari, todos los breves y bulas papales "a fuerza de tanto conceder concluyeron por no conceder nada, y ambas coronas, desde 1494, se vieron en la necesidad de buscar solución a sus pleitos coloniales mediante arreglos directos entre los dos países"24. En medio de este contexto de repartición del mundo, el Papa Gregorio XIII, mediante el breve de 1585 Ex pastorali officio había concedido a los jesuitas la exclusividad de la evangelización en Asia oriental. Esta exclusividad - que estuvo vigente hasta 1633, con la bula $E x$ debito pastoralis officii promulgada por el Papa Urbano VIII-, fue motivo de disputa entre las diferentes órdenes religiosas que pretendían evangelizar en Japón como también en China ${ }^{25}$. Aunque en 1586 el breve Dum ad uberes del Papa Sixto V había abierto a los franciscanos la posibilidad de predicar el evangelio ubique terrarum $^{26}$ - cláusula que fue interpretada como revocación del breve de Gregorio XIII—, los jesuitas siguieron defendiendo la exclusividad que les había sigo otorgada. En su Historia, Ribadeneria refiere en repetidas ocasiones las tensiones que se originaron debido a la entrada de misioneros franciscanos en Japón. Por ejemplo, cuando hace referencia a la llegada en 1593 de los franciscanos con fray Pedro Bautista al frente, escribe la tensión que se originó y cómo "los padres de la Compañía intimaron al gobernador un breve de Gregorio XIII en que mandaba con censuras que ningún religioso, ni persona eclesiástica, aunque sea obispo, entrase a predicar en Japón sin licencia de la Silla apostólica, salvo los padres de la Compañía"27. O también recoge la reticencia mostrada por los jesuitas cuando en 1595 los franciscanos consiguieron permiso para fundar una casa en Nagasaki. Señala Ribadeneria al respecto: “y como los frailes tenían licencia del rey, y con ella mucha libertad por dar testimonio de la fe, y los padres de la Compañía no la tenían, antes vivían con particular recelo, aunque no aflojaban en lo que tocaba a la conversión" ${ }^{28}$. Como señalan Santos y Lanzaco, los franciscanos se defendían argumentando que su entrada en Japón era lícita puesto que habían llegado allí no en calidad de "misioneros evangelizadores" sino como "embajadores" del gobernador de Manila en misión comercial ${ }^{29}$. De esta manera, justificaban que las atribuciones dictadas por las bulas papales no les afec-

24 Molinari, Diego Luis (1983): Desubrimiento y conquista de América. De Erik el Rojo a Hernán Cortés. Buenos Aires: Eudeba, p. 104.

25 Sobre la penetración de los franciscanos en China véase CerverA, José Antonio (2014): "Los intentos de los franciscanos para establecerse en China: siglos XIII-XVII”. En: Sémata, Ciencias Sociais e Humanidades, vol. 26, pp. 425-446. Acerca de la entrada de los franciscanos en Japón véase: Álvarez-TaLAdriz, José Luís (1979): "Notas para la historia de la entrada en Japón de los franciscanos". En: SÁnchez, Víctor / Fuertes, Cayetano S. (eds.): España en Extremo Oriente. Filipinas, China, Japón. Presencia franciscana 1578-1978. Madrid: Editorial Cisneros, pp. 3-32. La bibliografía relativa a las tensiones que se generaron con la entrada de los franciscanos en Japón y en China es abundantísima. Se reseñarán a continuación únicamente algunas de las publicaciones más relevantes. Cummins, James Sylvester (1986): Jesuits and friar in the Spanish expansion to the East. London: Variorum Reprint; Mungello, David E. (1985): Curious Land: Jesuit Accomodation and the Origins of Sinology. Stuttgart: Franz Steiner Verlag; Álvarez-Taladriz, José Luis (ed.) (1972): “Opinión de un canonista de la Compañía de Jesús sobre los Franciscanos en Japón”. En: Tenri Daigaku Gakuho, 23, Tokio, pp. $1-23$.

26 SAntos, Ángel S.J (1977): Las misiones bajo el patronato portugués (I). Madrid: Universidad Pontificia de Comillas, p. 588.

27 Ribadeneira, Marcelo de (1601): Historia ..., op. cit., p. 331.

28 Ibid., p. 352.

29 SAntos, Ángel S.J (1977): Las misiones..., op. cit., p. 590; Lanzaco Salafranca, Federico (2011): “Un siglo de comercio...", op. cit., on-line. 
taban dado que como emisarios diplomáticos su finalidad no era estrictamente la evangelización, salvando así las trabas jurídicas que pudieran existir.

\section{Japón en la Historia de Ribadeneira}

El texto de Ribadeneria sobre Japón debe enmarcarse en el contexto de las informaciones sobre este país que se escribieron durante el período Namban (1543-1639) a raíz de los contactos religiosos, mercantiles y diplomáticos que se establecieron ${ }^{30}$. Toda la documentación generada a partir de estos contactos constituye una fuente de información importante entre la que destaca, por ser más abundante y relevante, la documentación procedente de las órdenes religiosas. Seguramente ello se deba al hecho de que, como señala Barlés, la mayoría de los comerciantes estaban muy poco tiempo en el país, rara vez iban más allá de Nagasaki y sus alrededores, y su interés fundamental estaba en las transacciones mercantiles, no en aprender el idioma ni tampoco describir sus costumbres ${ }^{31}$. Los religiosos, en cambio, precisamente porque su objetivo era implementarse de una manera más duradera en Japón y poder así evangelizar a sus gentes, no sólo necesitaron entender el mundo al que accedían sino también tener un contacto más directo y estrecho con sus gentes. Por este motivo la documentación generada por los religiosos combina información relativa a los progresos de la fe cristiana en Japón con testimonios y descripciones de la vida y costumbres de su población. En este sentido, el relato de Ribadeneria no es ninguna excepción y en su obra combina las informaciones sobre los principales aspectos sociales, económicos, políticos y religiosos de Japón con las cuestiones relativas a la vida de los misioneros en aquel país y sus progresos en cuestiones de evangelización.

Como se ha indicado en el apartado anterior, el objetivo inicial de Ribadeneira es centrarse en la situación de la misión franciscana en este país y, por ello, en más de una ocasión refiere que se centrará en los asuntos relativos a la misión franciscana y a la provincia de San Gregorio Magno, que había sido creada en 1577 y cuya sede estaba en las Filipinas. Sin embargo, incorporará en su relato las "calidades del reino y de los moradores de él" ${ }^{\prime 2}$ tanto porque considera necesario esclarecer algunos aspectos de los que afirma existen informaciones que no le merecen credibilidad —en especial todos los temas vinculados con la religiosidad y ceremonias japonesas-, como también porque es consciente de la necesidad de conocer las costumbres del país para poder realizar las tareas de evangelización y de la curiosidad que existe acerca de las costumbres y características de este país. Ribadeneria ofrece un buen compendio sobre las principales características generales del reino y de su población, la organización social y política, la vida cotidiana, así como también sobre las principales ceremonias, sectas y formas de religiosidad del país. A continuación se

30 Para un conocimiento detallado y exhaustivo sobre la presencia española y portuguesa en Japón durante este período véase el excelente artículo BARLÉs, Elena (2003): "Luces y sombras en la historiografía del arte japonés en España". En: Artigrama, n 18 , pp. 23-82.

31 BARLÉs, Elena (2012): "El arte japonés desde la mirada de los misioneros de la Compañía de Jesús durante el Siglo Ibérico en Japón (1543-1640)”. En Zamora, María Jesús (ed.): Japón y España: acercamientos y desencuentros (Siglos XVI y XVII). Gijón: Editorial Satori, pp. 47-64.

32 Ribadeneira, Marcelo de (1601): Historia ..., op. cit., p. 321. 
presentarán de manera resumida los principales aspectos señalados por Ribadene$\mathrm{ria}^{33}$.

En cuanto a las características generales del reino, Ribadeneira señala la situación geográfica, su composición y la distancia a la que se encuentra con respecto a China. También el clima así como la fertilidad y abundancia de productos que tiene la tierra, a la vez que remarca que son variados y que están siempre disponibles en todas las ciudades. Otro aspecto en el que incide de manera importante es el tipo de casas y edificaciones que pueden encontrarse a lo largo del país. Desde la entrada de los francisanos en Japón, uno de los principales objetivos que tuvieron fue edificar iglesias y conventos en los que pudieran realizar de manera estable su labor evangelizadora, así como también hospitales en los que pudieran atender a los más desvalidos. En los primeros años, los franciscanos consiguieron edificar iglesias y hospitales en tres ciudades distintas, a saber, Kioto, Nagaski y Osaka. Es seguramente por este motivo que Ribadeneira confiere especial importancia a todo lo relacionado con las técnicas de construcción, los elementos estructurales de los edificios en Japón así como también las principales tipologías que existían ${ }^{34}$. Por ello, hay varias referencias a estos aspectos a lo largo de la Historia. Ribadeneira señala que las casas japonesas son bajas y de una única planta, que no se levanta directamente del suelo sino que se hace sobrealzada un poco del mismo, señalando como excepción los palacios de los gobernantes $^{35}$. A pesar de que señala de manera correcta el método de edificación, no incluye ninguna explicación que ayude a entender tal práctica, como podría ser el hecho de que elevar los edificios cuatro o cinco palmos del suelo favorecía su ventilación y ayudaba a mantener las estancias asiladas de la humedad. Ribadeneria tampoco hace referencia a los materiales comúnmente utilizados para la construcción - en este caso, la madera - a pesar de que señala que "los edificios de Japón son muy fáciles de hacer, y poco costosos" 36 , por lo que es posible que asociara el bajo precio y la facilidad constructiva con el uso de este material — sobre todo si se compara con el uso de materiales más pesados como pueden ser la piedra o el ladrillo y que eran los habituales en Occidente. La estructura de los edificios japoneses que explica Ribadeneira contrasta enormemente con las edificaciones religiosas que los franciscanos erigieron en Japón. En la construcción de los conventos e iglesias, los franciscanos siguieron los mismos modelos que en Occidente hasta el punto de que se hacían "a modo de los conventos de los Descalzos de Castilla"37. El resultado eran edificios altos que, evidentemente, sobresalían con respecto al resto de las edificaciones japonesas y en los que existían espacios claramente identificables tales como el claustro, las oficinas y las celdas de los religiosos, la iglesia y el coro. Esta diferenciación, señala el franciscano, "era muy alabada por los japoneses que la veían, por la traza nunca allá vista, antes que los religiosos se pasasen a ella venía todo género

33 Por cuestión de espacio se mencionarán únicamente los aspectos más relevantes señalados por Ribadeneria.

34 Sobre este asunto véase Busquets, Anna (2016): "El arte japonés del período Nabman (1543-1639) a través de la mirada de Marcelo de Ribadeneira”. En: Gómez, Anjhara (ed.): Japón y Occidente. El patrimonio cultural como punto de encuentro. Sevilla: Acongagua, pp.467-476; TAKizawA, Osami (2010): "El conocimiento que sobre el Japón tenían los europeos en los siglos XVI y XVII (I): Japón lugar de evangelización”. En: Cauriensia. Vol V, pp. 23-44; ArImura, Rie (2014): "The Catholic Architecture of Early Modern Japan: Between Adaptation and Christian Identity". En: Japan Review, n ${ }^{\circ}$ 27, Kioto, pp. 53-76.

35 Ribadeneira, Marcelo de (1601): Historia ..., op. cit., p. 322.

36 Ibid., p. 355.

37 Ibid., p. 342. 
de gente a verla" ${ }^{\prime 3}$. Esta era la manera habitual de proceder que tenían los religiosos con respecto a la construcción de conventos e iglesias en el territorio nipón, seguramente porque estos edificios cumplían con una función representativa en el ámbito religioso y, precisamente por ello, merecían estar a la vista de todos y ser referentes en cualquier asentamiento. En cambio, es curioso que en los otros edificios que levantaron, tales como los hospitales, los franciscanos siguieron el modelo japonés de construcción, es decir, edificios bajos y de una única planta ${ }^{39}$.

Sobre la población del reino, sus hábitos y costumbres, las noticias son más extensas y detalladas. Ribadeneira señala la buena apariencia y blancura de los japoneses. Este es un aspecto recurrente en las informaciones relacionadas con la población de Japón y la de China. En ambos casos, las descripciones señalan la buena apariencia de los hombres, remarcando especialmente la hermosura de las mujeres, y la blancura de la tez. El franciscano también explica la indumentaria y la manera de vestir, así como la importancia de la familia y del linaje o la habilidad que tienen con las armas y la ferocidad en el uso de las mismas ${ }^{40}$. Ribadeneira también refiere las bebidas más comunes que toman de entre las que destaca el hecho de que "el vino que tienen es todo de arroz" ${ }^{\prime 1}$ — referencia a la bebida japonesa del sake — y la importancia que conceden al té, tanto por sus propiedades como por la ritualidad que rodea a la ceremonia en la que se toma. Ribadeneira remarca la importancia social de esta bebida - hasta el punto de afirmar que "entre ellos es el mayor regalo que pueden dar a un huésped" ${ }^{2}$ _ y el hecho de que se trata de una costumbre muy extendida. A pesar de que Ribadeneira no explica la ceremonia del té (chanoyu), sí que incorpora en su relato algunos aspectos generales tales como la existencia de un espacio específico para la celebración de la ceremonia dentro de las casas (chashitsu), el uso de unos cuencos específicos para ingerir la bebida (chawan) o la ritualidad acerca de la preparación y los principales efectos de esta bebida para el cuerpo ${ }^{43}$. Ribadeneira también se muestra interesado por recopilar la información relativa a la ritualidad vinculada a las formas de enterrar que tienen y también a las principales fiestas del calendario japonés, de las que procura señalar el momento en el que se celebran, su duración, los principales manjares o la indumentaria utilizada. Por ejemplo, sobre la fiesta del Obon expone de manera clara los principales aspectos de la misma:

Otra fiesta hacen en la séptima luna en honra de sus difuntos, y llaman Bo, la cual dura tres o cuatro días, y en ellos visitan los templos de los ídolos, y de noche andan con gran ruido por las calles, llevando todos lamparillas encendidas. En esta fiesta hacen mucha comida de arroz y pescado, y pónenla a las noches en las

\footnotetext{
Ibidem.

"Muy en breve se levantó un hospital a modo de Japón". Ibidem.

40 Sorprende que Ribadeneria no incluya ningún juicio de valor. A raíz del tema del honor en Japón se limita a señalar que "son naturalmente feroces, amigos de cortar cabezas de hombres, y estiman tan poco la vida, que no se les da nada por perderla $[\ldots]$ cuando han de matar alguno que se tiene por honrado, primero que otro le corte la cabeza con unas espadas que llaman catanas, muy cortadoras, de que usan, tienen por gran honra, antes que otro le quite la cabeza, el cortarse ellos a sí mismos por la barriga". Ibid., p. 323.

$41 \quad$ Ibid., p. 324.

42 Ibid., p. 402.

43 "En sus casas también tienen jardines con algunos pinos y árboles tristes, y junto a ellos tienen un aposento toscamente labrado, adonde tienen vasijas en que tienen la cha, que es una hierba molida, y toda su fiesta es beber esto con agua caliente, con particulares y prolijas ceremonias, por ser bueno para la cabeza y el estómago". Ibid., p. 373.
} 
puertas de sus casas, y una linterna encendida para que vean a comer las almas de su antepasados, que dicen que vienen a comer ${ }^{44}$.

Sobre la organización política del reino, todas las informaciones están entremezcladas bien con la existencia de la figura política que denomina "rey" (Toyotomi Hideyoshi) y la riqueza en forma de casas y palacios de los que dispone; o bien con la presencia de un buen número de gobernantes locales con los que los franciscanos tuvieron que dirimir cada vez que querían crear o construir alguna iglesia. El resto de menciones a la organización política aparecen directamente vinculadas con el relato que hace de los contactos que hubo entre las autoridades de Manila y Japón.

Finalmente, en cuanto a los aspectos relacionados con la religiosidad Ribadeneria señala la existencia de un gran número de sectas y de un elevado número de sacerdotes - denominados "bonzos"-, que viven en comunidad y se sustentan a partir de las limosnas que reciben. Señala también la existencia de monjas que viven en comunidad, y la presencia de un sinfín de "dioses más pequeños, los cuales llaman camis y fotoques" ${ }^{45}$. Las informaciones que Ribadeneira proporciona están básicamente relacionadas con el budismo y a las diferentes expresiones que esta religión ya había tomado en esta época. Sin embargo, sus explicaciones no son siempre acordes con la realidad y con frecuencia cae en vaguedades y confunde algunas prácticas ${ }^{46}$. El parecer de Ribadeneria sobre la situación de la religión en Japón y el papel que juegan los monjes y monjas queda claro desde el primer momento. A pesar de que los monjes "engañan a los seglares, aficionándoles a los ídolos para llevarles las limosnas, aunque no sean muy aficionados a la idolatría" ${ }^{47}$, Ribadeneira considera que, en realidad, la población japonesa es "de buen entendimiento natural, y todos desean su salvación, cuando se les predica la ley de Dios Nuestro Señor, quieren que les convenzan con razones" ${ }^{\prime 4}$. Añade además que los japoneses, que hasta ese momento sólo habían conocido la fe cristiana por medio de los jesuitas, "gustaban oírles hablar de Dios, mostrándose muy agradecidos y aun admirados de ver que, siendo muchos de ellos letrados, se hiciesen como niños aprendiendo su lengua, por sólo enseñarles el camino del cielo"49. Y concluye que "comúnmente, cuando iban por los caminos salían de los lugares los cristianos a recibirlos, y si estaban trabajando en el campo y les veían pasar, aunque estuviesen lejos, les venían a besar el hábito y tomar la bendición" ${ }^{50}$. En este punto es importante remarcar un par de aspectos, ambos relacionados con la rivalidad ya mencionada que había entre los jesuitas y las órdenes mendicantes en Japón y en China. En primer lugar, la disputa que había en cuanto a los métodos de evangelización usados. Ribadeneira especifica de qué manera los frailes evangelizaban y predicaban en Japón con el propio ejemplo y ofrece numerosos casos de cómo tales métodos de predicación tuvieron buena acogida y

44 Ibidem.

45 Ibid., p. 363. Para un estudio acerca del uso de este vocablo en los textos de los siglos XVI y XVII véase CID LucAs, Fernando (2013): "Sobre el término Fotoque en la documentación ibérica de los siglos XVI y XVII". En: Kokoro: Revista para la difusión de la cultura japonesa, $\mathrm{n}^{\circ} 12$, pp. 22-24.

46 Por ejemplo, véase la explicación que hace de las principales figuras que adoran, Amida y Xaca. Véase RiBADENEIRA, Marcelo de (1601): Historia ..., op. cit., p. 325 y pp. 362-365.

47 Ibid., p. 325.

48 Ibidem.

49 Ibid., p. 389.

50 Ibidem. 
buenos resultados entre los japoneses. Escribe Ribadeneira: "Y aunque algunos de los cristianos, cuyos ánimos estaban poseídos del temor de la persecución pasada, condenaban por peligrosa y poco prudente la ostentación que los recién bautizados hacían, pero era tanto el deseo y fervor que tenían de morir por Jesucristo (a quien por la fe habían conocido) y amaban, que nada les atemorizaba" ${ }^{51}$.

En segundo lugar, Ribadeneria enfatiza en repetidas ocasiones su conocimiento de la lengua japonesa y el hecho de que él era capaz de predicar y enseñar usando dicha lengua. Señala Ribadeneira "con el favor del Señor supe en breve la lengua" 52 y añade que la aprendió para "predicar, aconsejar, adoctrinar y confesar a los japones, andando por las ciudades y aldeas circunvecinas" ${ }^{53}$. En cualquier caso, el religioso afirma la dificultad del idioma, del que señala que algunos invierten toda la vida en aprenderlo, y por ello en varias ocasiones menciona la presencia de intérpretes, especialmente cuando estaban ante el $\mathrm{rey}^{54}$. Sin duda alguna, la insistencia de Ribadeneira por demostrar su manejo de la lengua japonesa obedece a las críticas que los franciscanos habían recibido por no aprender la lengua japonesa cosa que, según sus oponentes, les impedía realizar una correcta predicación y señalaba la carencia de voluntad de permanecer en el país ${ }^{55}$.

\section{Consideraciones finales}

Fray Marcelo de Ribadeneria llegó a Japón procedente de Manila en la embajada que Luis Pérez Dasmariñas envió a Toyotomi Hideyoshi. Por lo tanto, se trata de un "viajero" cuyo primer objetivo en su llegada al país nipón fue entregar el presente que se les había dado en Manila. Este hecho, en parte, marcó la percepción que Ribadeneira tuvo de Japón o al menos, de una parte del mundo japonés, la relacionada con las esferas de poder. En este sentido, el franciscano señala en varias ocasiones la riqueza de las casas y edificios que eran propiedad del "rey" - así refiere en su Historia a Toyotomi Hideyoshi-, el buen trato que recibió como integrante de dicha embajada o los manjares que se servían en las casas en los que él y sus compañeros fueron recibidos.

Ahora bien, su viaje tuvo una segunda vertiente mucho más interesante para él, predicar y evangelizar entre los "infieles" de Japón. Por ello, en su Historia introduce abundantes detalles acerca de los progresos de la religión cristiana en dicho reino y de qué manera los franciscanos fueron ganándose el favor de los japoneses. En este punto, es necesario remarcar la defensa que el franciscano hace de los métodos usados por sus compañeros así como el énfasis que pone por demostrar su conocimiento de la lengua japonesa hasta el punto de que podía predicar y conversar sin problema alguno usando dicha lengua, pues este fue uno de los aspectos sobre el cual recibieron mayores críticas por parte de los jesuitas.

En cuanto a las informaciones sobre Japón que ofrece Ribadeneira éstas se centran fundamentalmente en los asuntos relacionados con la orden franciscana y los progresos realizados en Japón aunque, consciente de la curiosidad que este país po-

\footnotetext{
Ibid., pp. 359-362.

Ibid., pp. 350.

Ibid., pp. 537.

"Hablános el rey pocas palabras por un intérprete". Ibid., pp. 346.

Alvarez-Taladriz, J.L. (ed.): Documentos franciscanos ..., op. cit., p. 150.
} 
día suscitar en los lectores, el franciscano incorpora en su Historia algunos aspectos relacionados con las características generales del reino y su población, hábitos y costumbres, la organización interna del reino y las principales sectas y formas de religiosidad. 